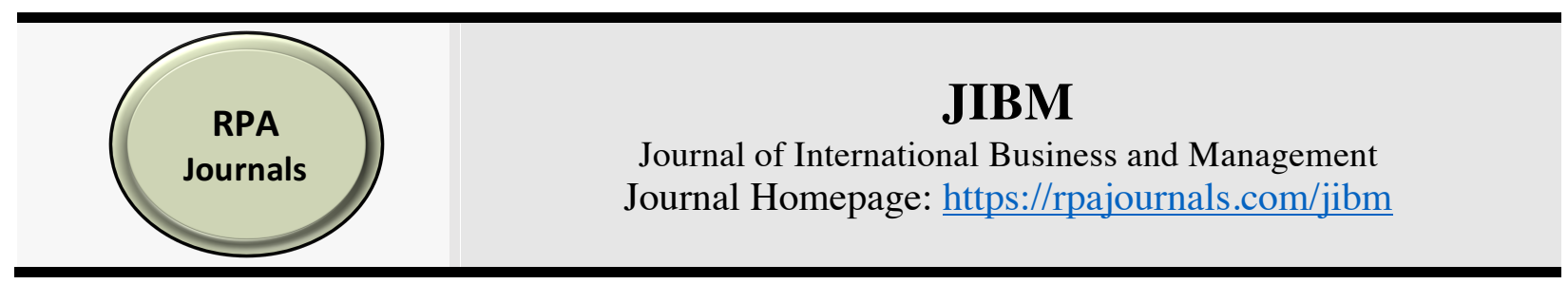

\title{
Exploring Challenges in Implementing Customer Relationship Management (CRM) for Customer Brand Engagement (CBE) in the Hospitality Industry: A Developing Country Perspective
}

\author{
Osman Monshi \\ University of the West of Scotland (UWS), United Kingdom
}

\begin{abstract}
Implementation of the customer relationship management (CRM) for greater customer brand engagement is always challenging in the organisations. However, there is a scarcity of these challenges in relation to the hospitality industry of Bangladesh, which is one of the fast-growing countries in Asia where the hospitality industry is growing in every year. Hence, exploring the challenges can be effective for the managers as well as researchers for decision making and conducting future research respectively. Therefore, this study aimed to identify the challenges in implementing CRM process for the greater for the CBE in the hotel organisations in the hospitality industry of Bangladesh. Based on the qualitative approach, this study carried semi-structured interviews among 12 marketing managers working in different hotels in Bangladesh. The study identified a lack of knowledge, cost of CRM implementation, lack of communication, incorrect implementation, changes in external forces as the major challenges. This study also identified some other challenges such as lack of technology integration, lack of clear objectives organisations, lack of training, absence of the clear, lack of defined goals of organisations. The concluding remarks with the implications of the study and its limitations have also been included at the end of the study.
\end{abstract}

Keywords: Customer Relationship Management (CRM), Challenges, Hospitality Industry, Bangladesh

*Corresponding author: Osman Munshi; Email: osmanmonshi@gmail.com

DOI: https://doi.org/10.37227/JIBM-2020-04-109

\section{Introduction}

The emergence of globalisation and technological advancement have facilitated buying process for customers from different local and international companies not only through the physical visit to the stores of those companies but also through the online processes at home (Reimann et al., 2010; Hollebeek et al, 2014;). As a result, the companies are facing highest competition ever that urges to formulate effective customer relationship management (CRM) so that the customers can stay for long with buying repeatedly while attracting the potential customers (Ramesh, 2013; Bhat and Darzi, 2016;). Hence, the companies also have to provide both excellent quality products and excellent customer service to ensure the customers are happy and satisfied to be a repeat customer (He et al, 2012; Leckie et al, 2016). In this regard, consumer brand engagement (CBE) has been newly emerged concept for the 
companies to improve or retain a strong and enduring relationship between the customers and brand through the shared values, experimental contents, rewards, interaction etc. that are also the antecedents of the CRM (Sin et al, 2005; Wang and Feng, 2012; Leckie et al, 2016).

CRM is called the integrated approach of tools and methodologies that support to the organizations manage customer relationship in the organised way (Johnson et al, 2012; Kim et al, 2012; Bhat and Darzi, 2016). CRM in the companies regardless of their industry enables identify main organisational activities and create planed and structured chart supported by technology and processes to offer customers products and services ensuring excellent quality (Ranjan and Bhatnagar, 2011; Li and Mao, 2012). Practitioners acknowledged that a well-developed CRM program is one the main approaches to making sure the consumers are benefitted (Boulding et al, 2005; Maklan et a, 2011; Nguyem and Simkin, 2013).

On the other hand, the consumer brand engagement is the process of forming an emotional and rational attachment between the consumer and brand (Algesheimer et al, 2005; Vivek et al, 2012; Romaniuk \& Nenycz-Thiel, 2013). Every company irrespective of the industry seeks to locate its brand name in the mind of customers therefore powerful research stream in the last three decades has emerged that highlights the dynamics and nature about certain consumer/brand relationships with the products or services (Aaker; Fournier 1998; Hollebeek, et al, 2014). However, positioning the brand of the customers in the customers' mind mostly depend on the CRM approaches implemented in the organisations. In this respect, implementation of CRM is the complicated process therefore, the organisations face challenging in developing CRM approaches for the better CBE. However, the challenging in implementing CRM is different according to organisations, industry, country, government and so on. Hence, it is viable to explore what are the specific or key challenging impacting on the CRM approach for the CBE development in the organisations in a particular industry.

This study particularly concentrates on the hospitality industry of Bangladesh, which is one of the developing countries. Bangladesh is located between South and Southeast Asia that has given a strategic geographical advantage of making her an entryway to both these markets. It is a beautiful country with many natural and historical attractive places most of which are recognised as UNESCO World Heritage Sites. Bangladesh has the largest mangrove forest, Sundarbans in the world with the longest sandy sea beach Cox's Bazar and it has also some islands especially St Martin's Island and Shandip (Amin, 2017; BPC, 2017). The country is also blessed with so many more attractive natural landscapes varying from the rolling hills and tea estates to the beautiful rivers in deltaic plains and along. Though she has lots of opportunities for promoting hospitality, the tourists find some difficulties to get the desired service from the service providers.

However, the country has experienced excellent growth in the tourism and hospitality industry by developing the resorts, picnic spots, transportation, security and other opportunities to visit the natural and historical places. In 2014, the contribution of the tourism and hospitality industry was more than $\$ 4$ billion that is expected to increase more than $\$ 5.5$ billion by 2025 to gain $1.9 \%$ of total GDP of Bangladesh (WTTC, 2017). Since the country is blessed with natural places with tourism values, therefore, the hospitality industry can get tremendous increased if the respective owners of hospitality organizations such as hotels, restaurants, resorts, motels, picnic spots etc improve their services while the government also ensure the security of the tourists visiting different tourist spots. Thus, it becomes a socio-economic obligation for the researcher to explores the challenging in implementing 
the CRM for the greater CBE so that the hospitality organisations in Bangladesh can overcome those challenges to implement for the better CBE.

\section{Literature Review \\ Bangladesh Tourism Industry and Why This Study Matters}

According to World Travel and Tourism Council (WTTC) (2017), the tourism and hospitality industry has created 292 million additional jobs worldwide and representing q in 10 jobs globally while generated 7.6 trillion, which is $10.2 \%$ of the global GDP. It will also be increasing in the next years since the people in the developing countries becoming economic solvent and looking for travelling in different tourist's spots for entertainment (Romaniuk \& Nenycz-Thiel, 2013). Most of the economies in the world are mostly depended on the tourism and hospitality industry, for example, UK, Spain, Maldives, France, United States, Greece, Italy, China, Egypt, Malaysia, Singapore etc (WTTC, 2017). There are many factors that attract tourists, who experience the hospitality services from the host country therefore it is very important for the countries to ensure determinants to ensure high standard hospitality for the tourists.

The companies in the western countries regardless of the industry always tend to ensure excellent customer satisfaction, therefore, their CRM approach is the strong and high standard that contributes to engaging consumers with their brands (Gambetti et al, 2015; Fang, 2008; De Villiers, 2015). For example, when a tourist examines the hospitality company in the Singapore or USA or the UK, he or she has a positive attitude towards the companies in the hospitality industry of those countries because all the companies in this industry tirelessly working for the better customer satisfaction through their CRM approach. Therefore, it is salient for the hospitality companies in the developing countries particularly in Bangladesh to use CRM practices for the development of the consumers' experience that will finally engage the consumer with the brand of the company. However, it is not easy to apply the CRM on the consumer brand engagement since there has been a lack of empirical results on how CRM can impact on the CBE for the greater benefits of the companies. This also urges of empirical research to identify the impact of CRM on the CBE in the hospitality industry.

The tourism and hospitality sector in Bangladesh has not made enough progress in the last few decades after its liberation from Pakistan in 1971 although it has valuable tourism prospective spots and resources. Due to the lack of infrastructure and lack of concentration on promotional activities through media are considered as the main barriers behind it. However, recent digitalisation of communication with other countries has contributed to the development of the promotional activities regarding the tourism prospects of the country. Moreover, the government of Bangladesh and some private companies have invested in the industry for the development overcall prospect of the industry. The government of Bangladesh has taken visionary approach for the development of the industry within next 10 years to spend $\$ 2.6$ bn by 2027 that will be $1.8 \%$ of total GDP of the country (WTTC, 2017). Thus, it can be expected that the country is going to be one of the key hosts for travellers for sightseeing and entertainment with fabulous tourism experiences that will contribute to the employment of the country.

In 2016, the contribution of the tourism and hospitality industry of Bangladesh to employment was incredible for example it was 3.8\% of total employment with $2,187,000$ jobs (WTTC, 2017). This is expected to rise by $1.8 \%$ to 2,695,000 jobs from 2017 to 2027 . Thus, the industry exposes excellent prospect for the economy and employment of Bangladesh that also urges for the development of the consumer or tourist experience while 
they are in the hospitality organisation. It can be possible when the practitioners in the tourism industry understanding how to apply the CRM approaches for the development of the consumer brand engagement through excellent services. Following graph presents the contribution of the tourism and hospitality industry adapted from WTTC report regarding prospects of Bangladesh.

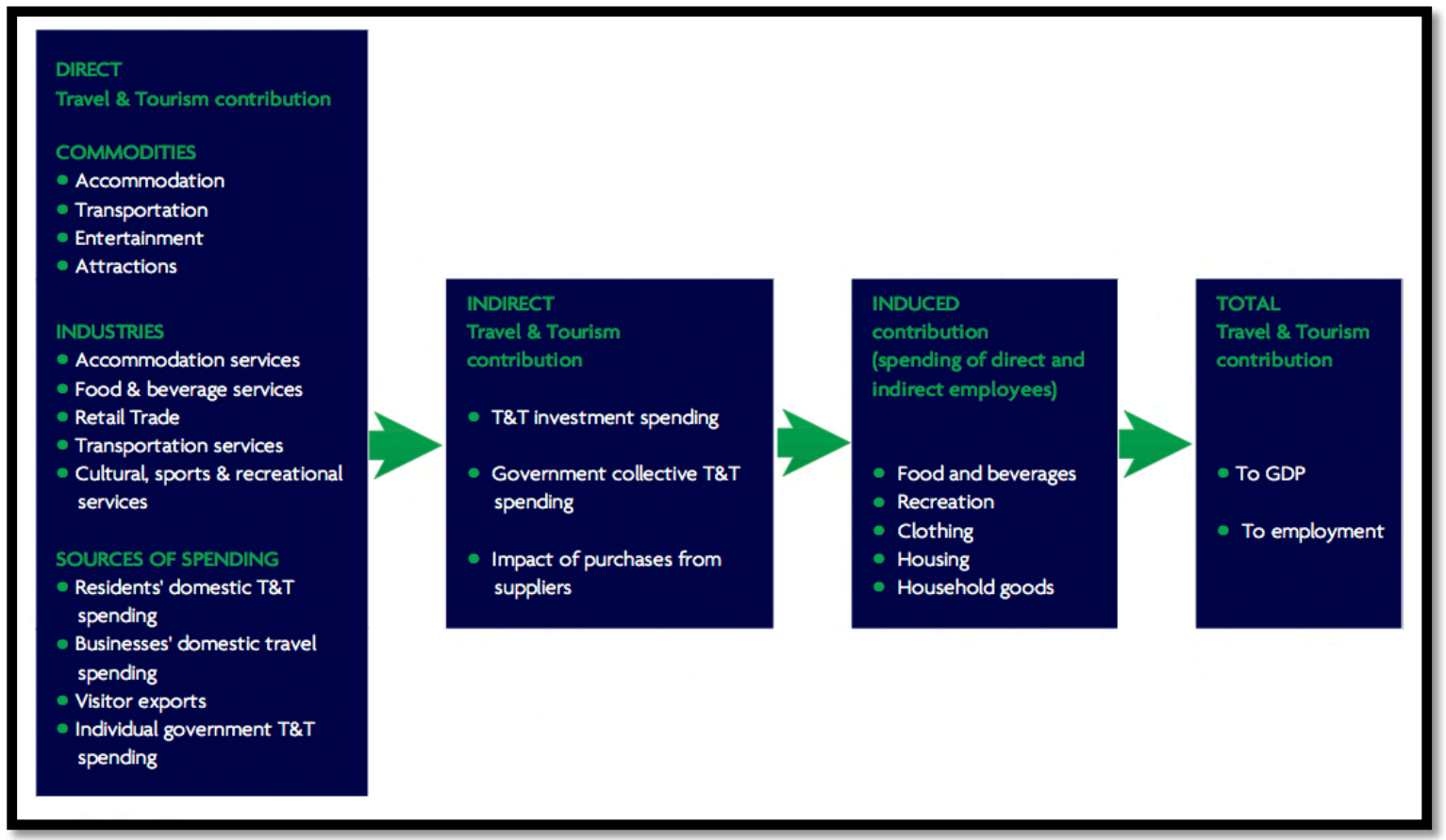

Source: WTTC, (2017)

According to Hudson and Hudson (2012), if a country of industry planners or other practitioners aim to gain money from the hospitality industry, it is very much important for them to the development of the customer satisfaction. In this regard, making customer satisfaction is not final aspects for gaining profit in a competitive environment, while the tourism industry has been one of the competitive industries worldwide (Iriana et al., 2013). Therefore, practitioners need to ensure there is enough CRM approach to build a relationship or to ensure engagement with customers in terms of brands. Thus, this study aims to find what are the challenges hindering the CRM approaches to be built for the greater consumer engagement in the Bangladeshi hospitality industry so that the industry can gain higher customer satisfaction.

\section{CRM and CBE and Challenges in Implementing CRM}

In mainstream literature, CRM construct has been conceptualized through the four different behavioural dimensions, which are Customer Orientation, CRM Organization, Knowledge Management and Technology -based CRM (Mohammad, et al 2013). Chang et al, (2010), created four activates of CRM practices that include sales support, analysis support, service support, data integration and access support. The advancement of technology, for example, the availability of the Internet, and the emphasis on branding techniques, CRM has become a key focus of branding (Palmatier et al., 2006; Payne \& Frow, 2005). Relationship marketing approaches in the companies provide a fundamental premise to the organizations and are a very vital element for the branding concept of the organisational stance in their respective industries (Grönroos, 1989, Morgan \& Hunt, 1994, Reichheld, 1996). Customer relationship and brand engagement often emphasize the importance of involvement, rapport, 
satisfaction, and commitment (De Villiers, 2015). In this regard, France et al, (2016) the most significant aspect of CBE include motivational level and brand-related state of the mind that is characterised through the certain level of behavioural, emotional, and cognitive activities in direct brand interactions. However, in the case of CRM and CBE, the behaviour of consumers and marketing conceptualizations are led by discussions of engagement as a process of building loyalty (France et al., 2016). Thus, this relationship creates significance notion of the link between CRM and CBE.

There are a number of challenges in implementing CRM in organisations. In this respect, Awasthi, Dubey, \& Sangle, (2014) outlined that there are mainly two types of CRM challenges that include classical and contemporary challenges. In this respect, classical challenging exists from the initial stage of CRM adoption in the organisations and when left unattended, affect the further addition of channels for CRM purposes (Awasthi, et al., 2014). The contemporary challenges outlined that when there are multiple channels provided to the customers for various services (Awasthi, et al., 2014). According to Aldaihani \& Ali, (2018) CRM has a significant impact on customer satisfaction, however, there are some challenges in implementing the CRM for example the technological challenges. On the other hand, various studies have recognised barriers of channel conflict whereby experiences of customers differ depending on the sales channel that also creates a challenge to the development of the organisational CRM implementation. According to Chen \& Popovich, (2003), CRM includes the people, process, technology that include the customers, therefore, it is very much challenging to create the interrelation among all these (Ahearne, Rapp, Mariadoss \& Ganesan, 2012; Deepak \& Jeyakumar, 2019). However, all the challenges in implementing CRM for the greater CBE in the organisations can be different due to the organisational, industrial, cultural, geographical and technological and other issues. Therefore, the dearth of literature relating to the challenges in relation to the hospitality industry creates a significant academic obligation to explore those challenges to fill the current gap.

\section{Research Methodology}

This study using qualitative approach collected 12 semi-structured interviews based on the convenience sampling to collect rich and real primary data from the managers working in different hotel organisations in the hospitality industry of Bangladesh (Islam, Hunt, Jantan, Hashim \& Chong, 2020). It is very much important to mention that all the managers, who were included in the interviews in this study. The recorded interviews were transcribed and member checking was also ensured so that the opinion of the participants can be reflected in the study. The data were manually analysed due to the smaller size of the sample. Firstly, the coding process was ensured to develop the categories that created a platform to develop the themes for the analysis and discussion.

\section{Analysis and Discussion}

This section contains the presentation and analysis of the primary data that has been collected through the interviews with the 12 managers from the hotel organisations to explore the challenges in implementing CRM approaches for the CBE in the hospitality industry of Bangladesh. The identified the key challenges have been outlined below: 


\section{Lack of Knowledge}

Out of 12 participants, 10 participants in this study acknowledge that most of the owners/board directors of the hotels in the hotels of the hospitality industry of Bangladesh do not know about mechanisms of the CRM approaches. The participant 3 has outlined as:

"I am working in this organisations since 2016 but I never see good CRM approaches to be applied in the hotel. It is because of the lack of knowledge about the effectiveness of the owner and he does not want to spend money. I try to convince but he does not listen and apply what I say about CRM and its benefits specially for the greater customer brand engagement (CBE). Therefore, I think implementing CRM is challenging only for the lack of knowledge."

The participant 8 also provided similar information that the higher management does not have much knowledge regarding the CRM approaches. Hence, the organisations are not practicing CRM approaches in a formal process. He outlined that:

"The owners think that doing good for the customers is enough and no need for the greater CRM practices. However, I believe the CRM practices in a formal process with the long-term planning could be good for the organisations like our hotel."

On the other hand, the participant 7 opined that:

"Many people have too much expectation to get the profit very soonest and cannot implement everything very quickly, therefore, it becomes very much challenging to implement the CRM approaches. Hence, it is very much important to the development of the organisational performance. The companies can also develop "

\section{Cost of the CRM Implementation}

All the participants in this study have outlined that the associated costs of the CRM implementation is a significant barrier in implementing the CRM in the organisations in Bangladesh specially in the hospitality industry. In this respect, the Participant 1 outlined that:

"The organisations in Bangladesh always concentrate to reduce the operational and other costs, hence, they strive to save money but the CRM implementation rather than the promotion to get more and more customers is expensive. Therefore, most of the hotels or the restaurants in the hospitality industry in Bangladesh would not be able to implement the CRM process. Hence, I would say it is very much challenging in implementing CRM in the hospitality industry of Bangladesh."

Mostly similar opinion was given by the $5^{\text {th }}$ participant, who opined that:

"Tourism industry i.e. hospitality industry is a growing industry in Bangladesh, therefore, many companies face challenge to develop the business position in the market due to the financial constraints. Therefore, it is very much challenging for the organisations to implement something that is expensive. In this respect, the financial constraints are very much important for the development of the organisational performance."

However, the participant 8 outlined that:

"CRM process is not an easy tasks and in Bangladesh CRM is not much important for many organisations because many of them do not have idea regarding the costeffectiveness of the CRM. Furthermore, the organisations also need to ensure that either the CRM practices have long-term impact or not to the development of the organisational performance because if the costs are not come out of it, then it becomes 
worst for the organisations. Therefore, most of the organisations are not presently interested to implement the CRM in the organisations."

\section{Lack of Communication}

Nine out of the 12 participants have outlined that the lack of communication is a significant challenge in implementation. In this respect, the participant 2 outlined that:

"Most of the employees in the hotels have a problem with the communication. The organisations have lack of communication processes as well as the lack of devices and internet facilities. As a result, the implementation process of the CRM becomes challenging for the organisations in the organisations of the hospitality industry."

The participant 5 opined that:

"Many managers and the owners do not have much idea about the significance of the social media communication process. They even do not like to promote the service websites and service features through the use of the social media platform such as Facebook, Twitter, Instagram and so on. You know in the modern era many young generation come to enjoy their holidays, however, very few of them depend on the traditional CRM approaches for example advertisement through the billboards or newspapers. In this respect, the social media communication is very much necessary for the greater success of the CRM."

In this respect, the Participant 9 added that:

"Most of the managers in our country are not technology oriented, hence, they are not using the communication technologies but these are very much important for the CRM implementation. Furthermore, the CRM process is mainly implemented through the regular communication and employees. In this respect, if the employees are not expert to use certain technologies, they will not be able to use the communication process. Therefore, it is urgent for the organisations to develop the communication process with the digitalisation."

\section{Incorrect Implementing}

Only 4 managers outlined that there are CRM approaches in the organisations but these are implemented incorrectly without making feasible target and plan. Thus, the CRM approaches do not get any successful end in the organisation.

Participant 9 outlined that:

"The previous manager in my hotel tried to implement the CRM approach in a formal process but he had to integrate the opinion of the higher management personnel, therefore, he was not able to implement in a correct process."

The participant 12 also quoted similar information and stated as:

"There are some hotels in the hospitality industry but most of them implement the CRM in a wrong process. As a result, they are not successful"

However, the participant 8 outlined that:

"We saw some organisations applied CRM approaches, however, all of them failed to get the best out of the CRM approaches probably because of the wrong. As a result, the interest of the many organisations have already reduced. Therefore, I would say implementation of the CRM would be very much challenging." 


\section{Changes in External Forces}

The market environment as well as external forces change frequently, therefore 7 participants have outlined that the CRM approach is not implemented in the hospitality industry, which is very much changing in nature. The participant 3 outlined that:

"The nature of the customers, competitors, government and other forces have been changing very much constantly, therefore, in such a changing environment, it is not possible to get the outcome from the CRM approach. Hence, many owners do not apply the CRM approach."

Changes in the external environment is also very much challenging for the organisations, that is also reflected from another participant of the study. The participant 8 has opined that:

"The pandemic, weather, natural disaster and so on are very significant issues that are taken into considerations in the decision making processes in the organisations "

The participants have also opined some other challenges that include lack of technology integration, lack of clear objectives of organisations, lack of training on the CRM and absence of the clear or defined goals of organisations. Most of the findings of the study are consistent with the previous studies, however, some of them are not consistent or unique findings (Ahearne et al., 2012; Muro et al., 2013; Aldaihani \& Ali, 2018). The financial problems and the lack of knowledge are the universal challenges in implementing anything new in the organisations, therefore, these are also very much important in the case of the implementation of the CRM (Muro et al., 2013; Awasthi et al., 2014).

\section{Concluding Remarks}

This study has identified that there are a number of significant challenges in implementing CRM process for the greater for the $\mathrm{CBE}$ in the hospitality organisations i.e. hotel organisations in the hospitality industry of Bangladesh. These include lack of knowledge, cost of CRM implementation, lack of communication, incorrect implementation, changes in external forces as the major challenges. This study also identified some other challenges such as lack of technology integration, lack of clear objectives organisations, lack of training, absence of the clear, lack of defined goals of organisations. Many of these findings are corroborated with the previous studies concerning CRM for the CBE in the different organisations. These findings create grounds for the academicians as well as researchers to research similar and other industries. Bangladesh is one of the fastest-growing economies in the world where the tourism and hospitality sector is growing fast but if the customers are not engaged with the brands, the respective organisations will not be able to gain profit in a long run. Hence, the findings of the study can be effective for the managers in preparing and implementing the CRM approaches for the greater CBE in the hotels. However, the smaller size of the findings is a major issue that restricts the limitation of the findings, which should not be generalised. In this respect, future studies in a similar context are suggested including bigger sample through the survey and quantitative analysis to develop the generalisability of the reported findings. 


\section{References}

Ahearne, M., Rapp, A., Mariadoss, B. J., \& Ganesan, S. (2012). Challenges of CRM implementation in business-to-business markets: A contingency perspective. Journal of Personal Selling \& Sales Management, 32(1), 117-129.

Aldaihani, F. M. F., \& Ali, N. A. B. (2018). Impact of Social Customer Relationship Management on Customer Satisfaction through Customer Empowerment: A Study of Islamic Banks in Kuwait. International Research Journal of Finance and Economics, 170, 41-53.

Algesheimer, R., Dholakia, U. M., \& Herrmann, A. (2005). The social influence of brand community: Evidence from European car clubs. Journal of Marketing, 69(3), 19-34.

Amin, S. (2017), "Enlivening the Tourism Industry in Bangladesh", available at: http://www.thedailystar.net/star-weekend/enlivening-the-tourism-industry-bangladesh1264555. (accessed 22 August 2020).

Awasthi, P., Dubey, N., \& Sangle, P. S. (2014). Contemporary challenges in CRM technology adoption: a multichannel view. International Journal of Electronic Customer Relationship Management, 8(1-3), 51-71.

Bhat, S., A., \& Darzi, M. A., (2016). Customer relationship management: An approach to competitive advantage in the banking sector by exploring the mediational role of loyalty, International Journal of Bank Marketing, 34(3), pp.388-410.

Boulding, W., Staelin, R., Ehret, M. \& Johnston, W. J. (2005). A Customer Relationship Management Roadmap: What Is Known, Potential Pitfalls, and Where to Go. Journal of Marketing, 69(4), 155-166.

Chen, I. J., \& Popovich, K. (2003). Understanding customer relationship management (CRM). Business Process Management Journal, 9(5), 672-688.

Chang, W., Park, J. E., \& Chaiy, S. (2010). How does CRM technology transform into organizational performance? A mediating role of marketing capability. Journal of Business Research, 63(8), $849-855$.

Deepak, R. K. A., \& Jeyakumar, S. (2019). Marketing Management. Educreation Publishing.

De Villiers, R. (2015). Consumer brand enmeshment: Typography and complexity modeling of consumer brand engagement and brand loyalty enactments. Journal of Business Research, $68,1953-1963$.

Fang, E. (2008). Customer participation and the trade-off between new product innovativeness and speed to market. Journal of Marketing, 72, 90-104.

France, C., Merrilees, B., \& Miller, D. (2016). An integrated model of customer-brand engagement: Drivers and consequences. Journal of Brand Management, 23, 119-136.

Gambetti, R., Biraghi, S., Schultz, D. E., \& Graffigna, G. (2015). Brand wars: Consumer-brand engagement beyond client-agency fights. Journal of Strategic Marketing, 1-14.

Gronroos, C. (1989). Defining marketing: A market-orientation approach. European Journal of Marketing, 23(1), 52-60.

He, H., Li, Y., \& Harris, L. (2012). Social identity perspective on brand loyalty. Journal of Business Research, 65(5), 648-657.

Hollebeek, L. D., Glynn, M. S., \& Brodie, R. J. (2014). Consumer brand engagement in social media: Conceptualization, scale development and validation. Journal of Interactive Marketing, 28, $149-165$.

Hudson, S., \& Hudson, L. (2012). Customer Service for Hospitality and Tourism. City: Goodfellow Pub Ltd.

Iriana, R., Buttle, F., \& Ang, L. (2013). Does organisational culture influence CRM's financial outcomes? Journal of Marketing Management, 29, 467-493.

Islam, M. A., Hunt, A., Jantan, A. H., Hashim, H., \& Chong, C. W. (2020). Exploring challenges and solutions in applying green human resource management practices for the sustainable workplace in the ready-made garment industry in Bangladesh. Business Strategy \& Development, 3(3), 332-343. 
Johnson, D. S., Clark, B. H., \& Barczak, G. (2012). Customer relationship management processes: How faithful are business-to-business firms to customer profitability? Industrial Marketing Management, 41, 1094-1105

Kim, M, Park, J, Dubinsky, A, \& Chaiy, S. (2012). Frequency of CRM implementation activities: a customer-centric view”, Journal of Services Marketing, 26(2), 83-93.

Leckie, C., Munyaradzi W. \& Lester W. (2016). Antecedents of consumer brand engagement and brand loyalty, Journal of Marketing Management, 32(5-6), 558-578.

Leckie, C., Nyadzayo, M. W. \& Johnson, L. W. (2016). Antecedents of consumer brand engagement and brand loyalty. Journal of Marketing Management, 32(5-6), 558-578.

Li, L., \& Mao, J. Y. (2012). The effect of CRM use on internal sales management control: An alternative mechanism to realize CRM benefits. Information \& Management, 49, 269-277

Maklan, S., Knox, S., \& Peppard, J. (2011). Why CRM fails - and how to fix it. MIT Sloan Management Review, 52(4), 77-85.

Mohammad, A. A., Rashid, B. B., \& Tahir, S. B. (2013). Assessing the influence of customer relationship management (CRM) dimensions on organization performance: An empirical study in the hotel industry. Journal of Hospitality and Tourism Technology, 4(3), 228-247.

Morgan, R., \& Hunt, S. (1994). The commitment-trust theory of relationship marketing. Journal of Marketing, 58(3), 20-38.

Muro, M. B., Magutu, P. O., \& Getembe, K. N. (2013). The strategic benefits and challenges in the use of customer relationship management systems among commercial banks in Kenya. European Scientific Journal, 9(13), 327-349.

Nguyen, B., \& Mutum, D. S. (2012). A review of customer relationship management: Successes, advances, pitfalls and futures. Business Process Management Journal, 18, 400-419.

Palmatier, R. W., Dant, R. P., Grewal, D., \& Evans, K. R. (2006). Factors influencing the effectiveness of relationship marketing: A meta-analysis. Journal of Marketing, 70(4), 136153.

Payne, A. and Frow, P. (2005). A strategic Framework for Customer Relationship Management, Journal of Marketing, 69(4), 167-176.

Ramesh, K. (2013). Role of customer relationship management in Indian banking system, International Journal of Applied Services Marketing Perspectives, 2(4), 645-650.

Ranjan, J., \& Bhatnagar, V. (2011). Role of knowledge management and analytical CRM in business: Data mining based framework. Learning Organization, 18(2), 131- 148

Reichheld, F. F. (1996). The loyalty effect. Boston, MA: Harvard Business School Press.

Reimann, M., Zaichkowsky, J., Neuhaus, C., Bender, T., \& Weber, B. (2010). Aesthetic package design: A behavioral, neural, and psychological investigation. Journal of consumer psychology, 20(4), 431-441.

Romaniuk, J., \& Nenycz-Thiel, M. (2013). Behavioral brand loyalty and consumer brand associations. Journal of Business Research, 66(1), 67-72.

Sin, L. Y. M., Tse, A. C. B. \& Yim, F. H. K. (2005). CRM: conceptualization and scale development," European Journal of Marketing, 39(11/12), 1264-1290.

Vivek, S. D., Beatty, S. E. \& Morgan, R. M. (2012). Customer engagement: Exploring customer relationships beyond purchase. Journal of Marketing Theory and Practise 20(2), 127-145.

Wang, Y., \& Feng, H., (2012), Customer relationship management capabilities: Measurement, antecedents and consequences, Management Decision, 50(1), 115-129.

WTTC, (2017), "Travel \& Tourism Economic Impact 2017 Bangladesh", available at: https://www.wttc.org/-/media/files/reports/economic-impact-research/countries2017/bangladesh2017.pdf. (accessed 20 August 2020) 